\title{
FRANCO Jr., Hilário - Os três dedos de Adão. Ensaios de Mitologia Medieval
}

José Mattoso

\section{(2) OpenEdition}

1 Journals

\section{Edição electrónica}

URL: http://journals.openedition.org/medievalista/617

DOI: 10.4000/medievalista.617

ISSN: 1646-740X

\section{Editora}

Instituto de Estudos Medievais - FCSH-UNL

\section{Refêrencia eletrónica}

José Mattoso, «FRANCO Jr., Hilário - Os três dedos de Adão. Ensaios de Mitologia Medieval », Medievalista [Online], 9 | 2011, posto online no dia 02 janeiro 2011, consultado o 22 setembro 2020 URL : http://journals.openedition.org/medievalista/617; DOI : https://doi.org/10.4000/medievalista 617

\section{(c) (†) (8)}

Mediavalista está licenciado com uma Licença Creative Commons - Atribuição-NãoComercial 4.0 Internacional 


\section{Titulo: Recensão}

FRANCO Jr., Hilário - Os três dedos de Adão. Ensaios de Mitologia Medieval. São Paulo: Editora da Universidade de São Paulo, 2010. Autor(es): José Mattoso

Enquadramento Institucional: Director da Medievalista Contacto: jjmtts@hotmail.com Fonte: Medievalista [Em linha]. №9, (Dezembro 2010). Direc. José Mattoso. Lisboa: IEM. Disponível em: http://www2.fcsh.unl.pt/iem/medievalista/ ISSN: 1646-740X

\section{Recensão}

FRANCO Jr., Hilário - Os três dedos de Adão. Ensaios de Mitologia Medieval. São Paulo: Editora da Universidade de São Paulo, 2010.

\section{José Mattoso}

Hilário Franco, fundador da Signo, a primeira (creio eu) revista brasileira de História medieval, tornou-se um medievalista de renome internacional. Situando-se deliberadamente na esteira de Jacques Le Goff e de Jean-Claude Schmitt, consagrou-se ao estudo do imaginário medieval nas suas expressões mais débil ou ambiguamente controladas pela vigilância clerical. Sem receio das inúmeras dificuldades que este terreno encerra, tem aí explorado temas e problemas pouco comuns. Os seus estudos anteriores, em concreto sobre o «País de Cocanha» (recreado por Rabelais) e sobre a 
«Eva barbada» (ou seja sobre a androginia de Adão-Eva) impuseram-no já como especialista destas matérias. $\mathrm{O}$ volume que apresentamos hoje, produto da reunião de doze ensaios, alarga a investigação, acrescentando-lhe temas análogos (entre eles o que dá o título ao livro) e propõe duas reflexões teóricas, uma sobre as relações entre «mentalidade e imaginário» e outra sobre o pensamento analógico medieval. Direi desde já que me parece uma contribuição de grande importância para orientar futuras investigações sobre temas e problemas de tais áreas, onde tanto a teoria como a prática são notoriamente inseguras ou pouco convincentes, quando não manifestamente inadmissíveis. O que já de si coloca o problema da carência de instrumentos adequados e de bons modelos de investigação para questões, por outro lado, tão importantes para compreender um sistema de pensamento que o progresso do pensamento científico tornou quase inacessível às pessoas da nossa época. O meu primeiro comentário é, pois, para sublinhar a importância da colectânea de HFJ.

$\mathrm{Na}$ mesma ordem de ideias, creio que se podem considerar como modelos de investigação sobre o imaginário medieval aquelas que HFJ efectua neste volume: o conceito de tempo na famosa «carta ao Preste João», o tema da escravidão espiritual na Legenda Aurea, o túmulo e o regresso à vida do Rei Artur, a papisa Joana, a simbologia de certos animais como as abelhas e o porco, o fruto proibido da árvore do Paraíso, o binómio Eva-Ave como figura do binómio Eva-Maria, a simbologia numérica que inspirou a edificação do claustro do mosteiro de Silos, e finalmente aquele problema que foi escolhido para dar o nome a esta colectânea, o significado do enigmático gesto de Adão representado por um capitel do mosteiro de San Juan de la Peña. O conjunto destes ensaios é significativo. Trata-se de expressões de crenças não sancionadas pelo clero acerca de uma realidade paralela à realidade visível do tempo e do espaço, a qual funciona com as suas regras, realidade essa que o homem experimenta em certas circunstâncias e que inspira algumas representações iconográficas cujo significado não é evidente para os homens de hoje. As suas manifestações visuais e literárias pressupõem a existência de tradições cujos vestígios se podem descortinar em textos literários, alusões em obras doutrinais, práticas ou rituais excluídos ou abandonados pelas instâncias clericais, figurações inesperadas, enfim, material folclórico que por vezes pode perdurar até aos nossos dias. Esse imaginário prolonga e recria tradições vindas da mais alta antiguidade, quer a sua expressão tenha sido aparentemente esquecida durante séculos para depois ressurgir inesperadamente, quer se tenha transmitido sem solução de 
continuidade; outras vezes aparece como representação nova mas com caracteres híbridos ou contaminados pelo pensamento racional, estruturalmente diferente.

Hilário Franco explora esse mundo meio selvagem com os melhores instrumentos, isto é, em primeiro lugar, com uma reflexão teórica em que procura definir as relações entre a mentalidade e o imaginário medieval e, em segundo lugar com um cuidadoso estudo sobre o pensamento analógico medieval. Beneficiando de uma discussão intensa, nem sempre segura, mas que parece ter chegado a alguns consensos e abandonado alguns desvios, HFJ define a mentalidade como área de intersecção entre o biológico e o social, dominada por mecanismos emocionais que a torna o nível mais estável das sociedades; por isso gera automatismos e formas de pensamento que abarcam a totalidade do comportamento humano. É sobre tal estrutura que se forma o imaginário, ou seja, o sistema de imagens que traduz historicamente e de forma segmentada o intemporal e o universal tal como o concebiam os indivíduos da Idade Média ocidental.

O segundo instrumento utilizado por HFJ é o recurso constante a testemunhos da literatura medieval, quer da literatura narrativa, quer da literatura religiosa e doutrinal, mesmo os mais técnicos ou eruditos. Fá-lo com grande conhecimento de causa, isto é recorrendo quer a textos muito conhecidos, quer a obras secundárias, marginais, apócrifas, menores, acessórias. Acrescentemos ainda que demonstra um conhecimento muito alargado da bibliografia antropológica e que recorre frequentemente a uma argumentação linguística invulgar. Nestas condições pode-se apresentar a sua obra como uma excelente introdução ao estudo do perigoso campo do imaginário medieval.

Perigoso, na verdade, porque o cruzamento de dados se torna por vezes de tal modo labiríntico, que é impossível perceber se as suas soluções para os problemas apresentados podem ou não ser aceites sem receio de erro. Tomemos, por exemplo, o caso da interpretação numérica baseada no carácter privilegiado do número oito que teria inspirado os construtores do claustro do mosteiro de Silos, perto de Burgos. A sua demonstração acerca do carácter privilegiado do simbolismo do número oito é brilhante. Os argumentos acerca desse pressuposto no número de capitéis do claustro e a notável explicação acerca do mesmo pressuposto na forma e elementos da patena do fím do século XI procedente da mesma abadia não deixam dúvidas acerca da importância que os monges de Silos da mesma época atribuíam a tal número. Mas que função tinha esse pressuposto no pensamento ou na espiritualidade dos monges? As especulações de HFJ

Medievalísta online $N^{\circ} 9 \mid$ Janeiro - Junho 2011 ๑ IEM - Instituto de Estudos Medievais 3 www2.fcsh.unl.pt/iem/medievalista 
acerca do sentido das representações dos capitéis, deduzidas da ordem em que se encontram uns em relação aos outros, são bem menos convincentes. Parecem ser uma tentativa de racionalização de uma estrutura mental que para nós está, talvez, irremediavelmente perdida. Não sei se não seria preferível admitir que o número oito tem simplesmente um sentido ritual, encantatório, sacramental (ou mesmo mágico). Isto é, a imersão do monge na estrutura octogonal do claustro criaria só por si um veículo de contacto com o sobrenatural, uma forma de induzir a experiência vivencial, contemplativa ou mística. Se assim é, a interpretação das cenas dos capitéis como luta escatológica entre os exércitos celestes e as forças demoníacas, da vegetação do Paraíso, da folha de acanto como símbolo do pecado carnal, das aves sobrepostas como representação da avareza e da luxúria, do grifo como metáfora cristológica, tudo isso se torna supérfluo. Podem ser apenas representações das forças opostas a que o homem está sujeito; e a sua representação, por sua vez, constituir uma forma de catarse.

As oito divisões e as séries circulares de oito pedras preciosas da patena de Silos talvez tenha, de facto uma relação mais directa com a divisão da hóstia em oito partes, característica da liturgia hispânica. Mas esta hipótese só viria reforçar a função ritual ou sacramental do claustro quadrado com as suas $64(8 \times 8)$ colunas e outros tantos capitéis.

De outro género são as minhas dúvidas acerca do erudito estudo de HFJ acerca do gesto do Adão representado no capitel de San Juan de la Peña. Que se trate de uma forma de evocar o pecado original, e que essa forma tenha alguma coisa que ver com a tradição de Adão se ter engasgado ao comer o fruto da árvore da vida - o que explicaria a cartilagem da tiróide masculina popularmente conhecida como «maçã de Adão» - é admissível. Mas ir mais longe, e explicar o gesto deste Adão que leva a mão direita ao pescoço, estende três dedos e encolhe os restantes, como uma forma de protesto contra a imposição do rito romano e uma confissão de fidelidade ao dogma trinitário já é mais difícil de aceitar. Neste caso, os argumentos de HFJ baseados no seu profundo conhecimento das fontes, da história monástica e eclesiástica da região, da iconografia e da literatura da época não me parecem ser suficientes para transformar uma explicação simplesmente possível numa hipótese provável.

Ora esta navegação através dos mares da simples possibilidade torna-se, por vezes, não tanto viagem de reconhecimento, mas convite à construção de miragens. É demasiado evidente o risco corrido por quem tome à letra o princípio baseado em $\mathrm{M}$. 
Bloch e invocado por HFJ de que «as hipóteses científicas não são derivadas de fatos observados e sim inventadas para torná-los compreensíveis» - o que é verdade, mas exige a descoberta de fatos efectivamente documentados e efectivamente demonstrativos; já não o é (a não ser em contexto pós-modernista) o princípio daí deduzido de que o historiador é um «construtor de hipóteses inverificáveis» (p. 377). Tratava-se de descobrir uma explicação para o gesto de Adão. Apesar do material acumulado, HFJ acaba por considerar os resultados da sua investigação como insuficientes. Todavia não deixa de propor a sua interpretação como se bastasse ser verosímil para se tornar verdadeira.

Estas críticas, no entanto, não devem prevalecer sobre as qualidades da obra de HFJ. A sua colectânea é um bom exemplo de uma pesquisa frutuosa e normalmente bem conduzida na floresta do imaginário folclórico medieval. Os seus estudos acerca dos temas que escolheu e que são, na verdade, muito sugestivos como contraponto do pensamento racional usado na teologia escolástica, podem-se considerar, na minha opinião, como verdadeiramente exemplares para a reconstituição de uma forma peculiar de mentalidade e do especial funcionamento de um imaginário sempre complexo e mutável. Com as devidas cautelas, não posso deixar de recomendar sua obra a quem o quer seguir.

\section{COMO CITAR ESTE ARTIGO}

\section{Referência electrónica:}

MATTOSO, José - FRANCO Jr., Hilário - Os três dedos de Adão. Ensaios de

Mitologia Medieval. São Paulo: Editora da Universidade de São Paulo, 2010.

Medievalista [Em linha]. N9, (Dezembro de 2010). [Consultado dd.mm.aaaa].

Disponível em

http://www2.fcsh.unl.pt/iem/medievalista/MEDIEVALISTA9\mattoso9001.html. ISSN 1646-740X. 
Recensão • José Mattoso

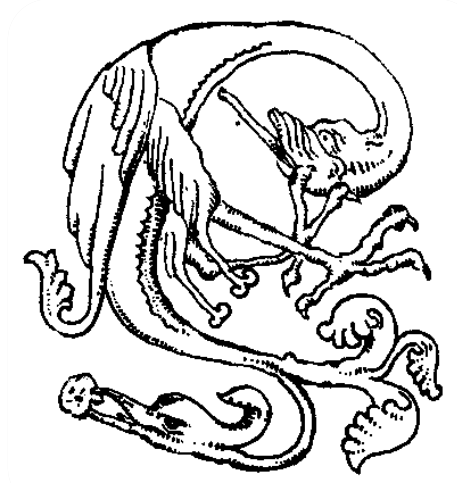

Medievalista online №9| Janeiro - Junho 2011 (c) IEM - Instituto de Estudos Medievais 6 www2.fcsh.unl.pt/iem/medievalista 